\title{
Experimental Study on the Cohesional Strength between Old and New Pavement Concrete
}

\author{
Rui Zeng 1,2,3, A, Yong Zhang 1,A, Chao Zhang 1,B, Jie Li ${ }^{1, B}$ \\ 1Department of Airfield Engineering, Air Force Logistics College, Xuzhou 221000, China \\ ${ }^{2}$ Field Engineering College of PLA University of Science and Technology, Nanjing, 210007, China \\ ${ }^{3}$ School of Mechanical and Electrical Engineering, China University of Mining and Technology, \\ Xuzhou 221008, China \\ azri1980@126.com, b79450724@qq.com
}

\begin{abstract}
Keywords: concrete; cohesional strength;maintenance of pavement; interface agent
Abstract. The effects of old and new pavement concrete cohesional strength by different concrete surface processing mode, types of interface agent and cycle of freezing and thawing were studied through experiments and theoretical analysis to test the old and new pavement concrete cohesional strength under the ambient temperature and freezing and thawing environment. The experiments show that the interface agent has great influences on the concrete surface cohesional strength and cement paste has the best bonding effect. The old and new pavement concrete has poor frost resistance, and the compression and rupture strength of the cohesional surface are lowest under the cement-sand mortar interface agent mode. After chipping treatment, the frost resistance ability is better than the brushing treatment's.
\end{abstract}

\section{Introduction}

The airport pavement is the area which surports the plane to take off, landing and maintenance. The pavements are influenced by natural condition and load factors, and part of airport pavements are damaged seriously ${ }^{[1]}$. The maintenance and reinforcement of the airport pavements is important, but the old and new pavement concrete cohesional strength is not enough, which causes patch spalling and problems of construction quality ${ }^{[2,3]}$. In this paper, the concrete cohesional strength under the ambient temperature and freezing and thawing environment was studied through experiments and theoretical analysis to provide theoretical basis for the maintenance and reinforcement of the airport pavement.

\section{Indoor Test}

\subsection{Material Selection and Experimental Device of Old and New Concrete}

2.1.1 Material Selection. (1) The old concrete used PC32.5\# ordinary portland cement which was producted in Xuzhou Zhonglian cement plant. The new concrete used PC42.5\# ordinary portland cement which was producted in Xuzhou Zhonglian cement plant. The relative density of cement is $3.10 \mathrm{~g} / \mathrm{cm}^{3}$, and the specific area is $310 \mathrm{~m}^{2} / \mathrm{kg}$.

(2) The old concrete coarse aggregate used the continuous grading crushed stone of 5 40mm.

(3) The fine aggregate used yellow ground, the fineness modulus of which is 2.85 , and sediment percentage is less than $1.8 \%$.

(4) The interface agent uesd the level I flyash mixed with cement paste.

2.1.2 Experimental Device. The experimental devices are universal hydraulic servo testing machine and KDR-V9 concrete rapid freezing and thawing test machine.

2.2 Cohesional Surface and Interface Agent. Considering the operational simplicity and the experimental representation, the treated old concrete surface was divided into $\mathrm{N}$ type and $\mathrm{Z}$ type, which was the bonding surface.

(1) N type. The old concrete surface was brushed by wire brush, and cleaned by water.

(2) $\mathrm{Z}$ type. The old concrete surface was treated by chipping, and cleaned by water. 
3 interface agents were used in the experiments.

(1) Cement paste. PC42.5\# ordinary portland cement producted byXuzhou Zhonglian cement plant, and the water cement ratio is 0.4 .

(2) Cement-sand mortar. The water cement ratio is -0.4 , and the cement-sand ratio is $1: 1$.

(3) Mixed cement paste. The water cement ratio is 0.4 , and the fly ash is the $10 \%$ weight of the cement

2.3 Experiment Scheme. The experiments were divided into two series each of which has 12 groups, and each group has three $100 \times 100 \times 100 \mathrm{~mm}^{3}$ cube compressive tests and three $100 \times 100 \times 400 \mathrm{~mm}^{3}$ prism rupture tests. The experiments were respectively carried under the ambient temperature and freezing and thawing environment.

The old and new concrete tests numbers are shown in Table 1.

Table 1 Tests numbers

\begin{tabular}{ccc}
\hline number & cohesional surface & interface agent \\
\hline NC0,NC1,NC2 & & cement paste \\
NS0,NS1,NS2 & brushing surface & $\begin{array}{c}\text { cement-sand mortar } \\
\text { mixed cement paste }\end{array}$ \\
NF0,NF1,NF2 & & cement paste \\
ZC0,ZC1,ZC2 & chipping surface & $\begin{array}{l}\text { cement-sand mortar } \\
\text { mixed cement paste }\end{array}$ \\
ZF0,ZF1,ZS2 & & mix2
\end{tabular}

The compression and rupture strength experiments were done on the universal hydraulic servo testing machine, and the freezing and thawing cycle was experiments were done on KDR-V9 ${ }^{[4]}$.

\section{Test Result Analysis}

The cohesional surface strength under the ambient temperature is shown in Table 2, and under freezing and thawing environment is shown in Table 3.

Table 2 The cohesional surface strength under ambient temperature

\begin{tabular}{|c|c|c|c|c|c|c|c|c|c|}
\hline \multirow[b]{2}{*}{ numbe } & \multicolumn{3}{|c|}{ cohesional surface parameter } & \multicolumn{3}{|c|}{ compression strength } & \multicolumn{3}{|c|}{ rupture strength } \\
\hline & $\begin{array}{c}\text { cohesional } \\
\text { area }(\mathrm{cm} \times \mathrm{cm})\end{array}$ & $\begin{array}{c}\text { Harshness } \\
(\mathrm{mm})\end{array}$ & $\begin{array}{l}\text { mean } \\
\text { value }\end{array}$ & $\begin{array}{c}\begin{array}{c}\text { Loading } \\
(\mathrm{kN})\end{array} \\
\end{array}$ & $\begin{array}{l}\text { Strength } \\
\text { (MP) }\end{array}$ & $\begin{array}{l}\text { mean } \\
\text { value }\end{array}$ & $\begin{array}{c}\begin{array}{c}\text { Loading } \\
(\mathrm{kN})\end{array} \\
\end{array}$ & $\begin{array}{l}\text { Strength } \\
\text { (MP) }\end{array}$ & $\begin{array}{l}\text { mean } \\
\text { value }\end{array}$ \\
\hline $\mathrm{NCO}$ & $9.9 \times 10.1$ & 0.52 & & 153 & 15.3 & & 5.2 & 1.56 & \\
\hline $\mathrm{NC} 1$ & $10 \times 9.9$ & 0.53 & 0.51 & 164 & 16.4 & 15.2 & 5.6 & 1.68 & 1.55 \\
\hline $\mathrm{NC} 2$ & $10.1 \times 9.8$ & 0.49 & & 138 & 13.8 & & 4.7 & 1.41 & \\
\hline NSO & $10.2 \times 9.9$ & 0.48 & & 113 & 11.3 & & 4.4 & 1.32 & \\
\hline NS1 & $9.7 \times 10.1$ & 0.51 & 0.48 & 102 & 13.2 & 11.7 & 4.7 & 1.41 & 1.33 \\
\hline NS2 & $9.8 \times 10$ & 0.47 & & 106 & 10.6 & & 4.2 & 1.26 & \\
\hline NF0 & $9.8 \times 10.1$ & 0.52 & & 136 & 13.6 & & 4.8 & 1.44 & \\
\hline NF1 & $10 \times 9.9$ & 0.53 & 0.53 & 139 & 13.9 & 13.4 & 5.0 & 1.50 & 1.52 \\
\hline NF2 & $9.6 \times 10.2$ & 0.54 & & 128 & 12.8 & & 5.4 & 1.62 & \\
\hline $\mathrm{ZC} 0$ & $9.8 \times 10.2$ & 3.3 & & 215 & 21.5 & & 11.8 & 3.54 & \\
\hline $\mathrm{ZC} 1$ & $10 \times 9.7$ & 3.5 & 3.5 & 222 & 22.2 & 22.8 & 12.4 & 3.72 & 3.69 \\
\hline $\mathrm{ZC} 2$ & $10.1 \times 9.9$ & 3.7 & & 248 & 24.8 & & 12.7 & 3.81 & \\
\hline ZSO & $9.9 \times 9.8$ & 2.8 & & 144 & 14.4 & & 10.3 & 3.09 & \\
\hline ZS1 & $9.7 \times 10.2$ & 3.6 & 3.2 & 186 & 18.6 & 16.7 & 11.6 & 3.48 & 3.28 \\
\hline ZS2 & $10.1 \times 9.6$ & 3.2 & & 171 & 17.1 & & 10.9 & 3.27 & \\
\hline ZF0 & $9.8 \times 10.1$ & 2.9 & & 165 & 16.5 & & 10.5 & 3.15 & \\
\hline ZF1 & $9.9 \times 10.2$ & 3.3 & 3.1 & 201 & 20.1 & 18.6 & 11.7 & 3.51 & 3.37 \\
\hline $\mathrm{ZF} 2$ & $9.8 \times 10.1$ & 3.1 & & 192 & 19.2 & & 11.5 & 3.45 & \\
\hline
\end{tabular}


Table 3 The cohesional surface strength under freezing and thawing environment

\begin{tabular}{|c|c|c|c|c|c|c|c|c|c|c|c|}
\hline \multirow[b]{2}{*}{ numbe } & \multirow{2}{*}{$\begin{array}{c}\text { mean } \\
\text { harshness }\end{array}$} & \multirow{2}{*}{$\begin{array}{l}\text { freezing } \\
\text { time }\end{array}$} & \multicolumn{3}{|c|}{ weight loss rate(\%) } & \multicolumn{3}{|c|}{ compression strength } & \multicolumn{3}{|c|}{ rupture strength } \\
\hline & & & wo & Wn & $\mathrm{W}$ & $\begin{array}{l}\text { Loading } \\
(\mathrm{kN})\end{array}$ & $\begin{array}{l}\text { Strength } \\
\text { (MP) }\end{array}$ & $\begin{array}{l}\text { mean } \\
\text { value }\end{array}$ & $\begin{array}{c}\begin{array}{c}\text { Loading } \\
(\mathrm{kN})\end{array} \\
\end{array}$ & $\begin{array}{l}\text { Strength } \\
\text { (MP) }\end{array}$ & $\begin{array}{l}\text { mean } \\
\text { value }\end{array}$ \\
\hline $\mathrm{NC} 0$ & \multirow{3}{*}{0.5} & \multirow{3}{*}{10} & 9.81 & 9.85 & -0.5 & 113 & 11.3 & \multirow{3}{*}{11.2} & 5.2 & 0.97 & \multirow{3}{*}{0.95} \\
\hline NS0 & & & 9.80 & 9.90 & -1 & 124 & 12.4 & & 5.6 & 1.02 & \\
\hline NF0 & & & 9.93 & 9.96 & -0.3 & 98 & 9.8 & & 4.7 & 0.87 & \\
\hline $\mathrm{NC} 1$ & \multirow{3}{*}{0.4} & \multirow{3}{*}{20} & 9.92 & 10.0 & -0.8 & 96 & 9.6 & \multirow{3}{*}{9.4} & 4.4 & 0.54 & \multirow{3}{*}{0.56} \\
\hline NS1 & & & 9.82 & 9.91 & -0.9 & 99 & 9.9 & & 4.7 & 0.63 & \\
\hline NF1 & & & 9.75 & 9.82 & -0.7 & 88 & 8.8 & & 4.2 & 0.51 & \\
\hline $\mathrm{NC} 2$ & \multirow{3}{*}{0.5} & \multirow{3}{*}{40} & 9.96 & 9.92 & 0.4 & 75 & 7.5 & \multirow{3}{*}{7.5} & 4.8 & 0.39 & \multirow{3}{*}{0.37} \\
\hline NS2 & & & 9.83 & 9.77 & 0.6 & 72 & 7.2 & & 5.0 & 0.27 & \\
\hline NF2 & & & 9.95 & 9.90 & 0.5 & 79 & 7.9 & & 5.4 & 0.45 & \\
\hline $\mathrm{ZC} 0$ & \multirow{3}{*}{3.3} & \multirow{3}{*}{10} & 9.96 & 9.99 & -0.3 & 155 & 15.5 & \multirow{3}{*}{16.8} & 11.8 & 1.68 & \multirow{3}{*}{1.69} \\
\hline ZS0 & & & 9.92 & 10.0 & -0.8 & 162 & 16.2 & & 12.4 & 1.56 & \\
\hline ZF0 & & & 9.87 & 9.91 & -0.4 & 188 & 18.8 & & 12.7 & 1.83 & \\
\hline $\mathrm{ZC} 1$ & \multirow{3}{*}{3.1} & \multirow{3}{*}{20} & 9.92 & 9.99 & -0.7 & 115 & 11.5 & \multirow{3}{*}{13.6} & 10.3 & 1.08 & \multirow{3}{*}{1.13} \\
\hline ZS1 & & & 9.81 & 9.89 & -0.8 & 151 & 15.1 & & 11.6 & 1.32 & \\
\hline $\mathrm{ZF} 1$ & & & 9.72 & 9.81 & -0.9 & 142 & 14.2 & & 10.9 & 0.99 & \\
\hline ZC2 & \multirow{3}{*}{2.9} & \multirow{3}{*}{40} & 9.85 & 9.80 & 0.5 & 98 & 9.8 & \multirow{3}{*}{10.2} & 10.5 & 0.81 & \multirow{3}{*}{0.82} \\
\hline ZS2 & & & 9.92 & 9.86 & 0.6 & 113 & 11.3 & & 11.7 & 0.93 & \\
\hline ZF2 & & & 9.97 & 9.93 & 0.4 & 95 & 9.5 & & 11.5 & 0.72 & \\
\hline
\end{tabular}

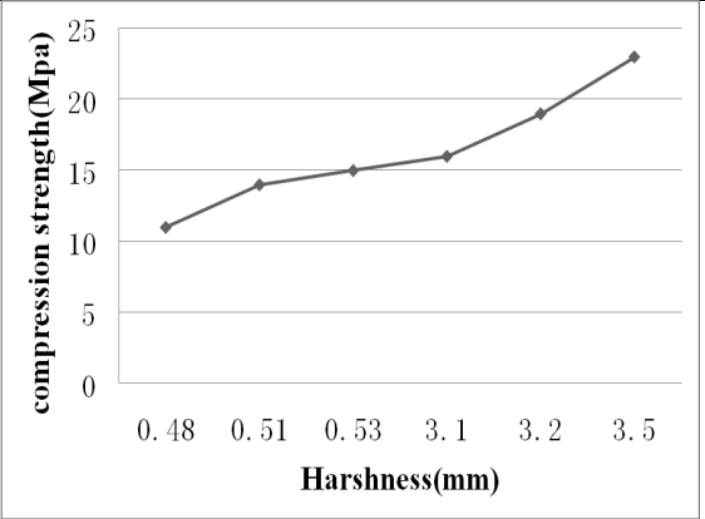

Fig.1 Diagram of compression strength and harshness

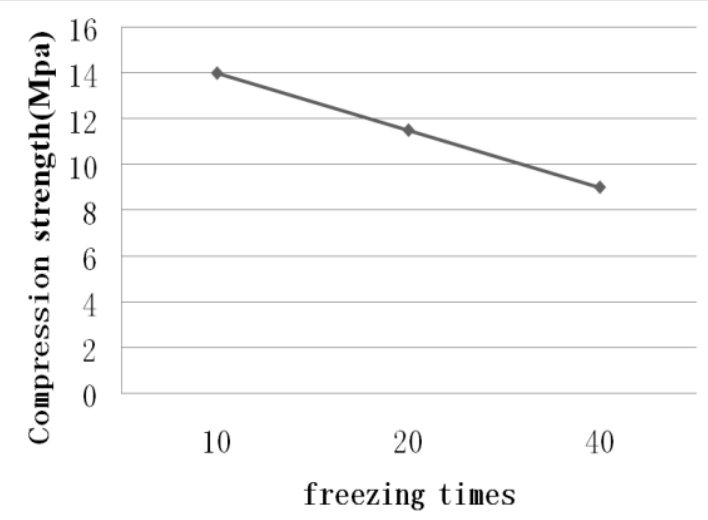

Fig.3 Diagram of compression strength and freezing times

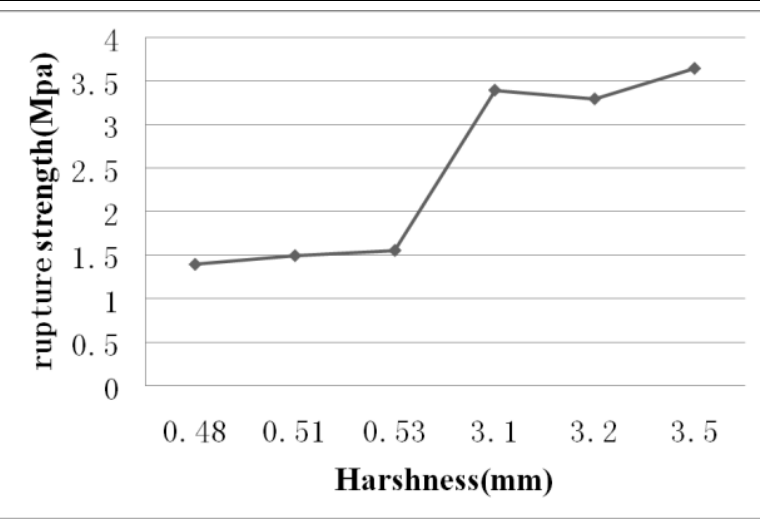

Fig.2 Diagram of rupture strength and harshness

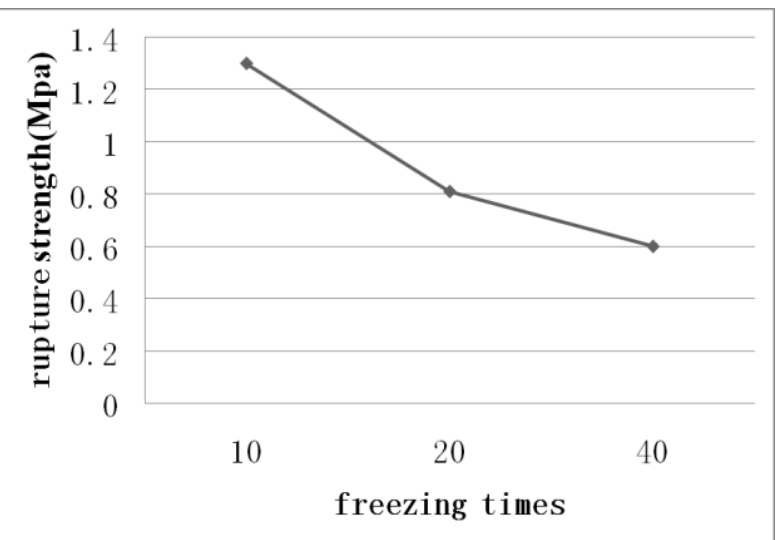

Fig.4 Diagram of rupture strength and freezing times

3.1 Effects of surface treatment method. Through the analysis of Table1 and Table2, the relationship between compression strength and harshness could be shown as Fig.1 and Fig.2. It is clearly can be seen that the harshness has great influences on compression and rupture strength of the cohesional surface. The chipping surface harshness is higher than the brushing surface's, so the chipping surface cohesional area is bigger, which means the cohesional strength is higher.

3.2 Effects of freezing and thawing cycle. According to the rapid freezing test, the relationship between compression strength and freezing times could be shown as Fig.3 and Fig.4. It is clearly can 
be seen that the freeze-thaw action has great influences on compression and rupture strength of the cohesional surface, old concrete, amd new concrete. With the increasing of freezing and thawing cycle times, the compression and rupture strength of the cohesional surface, old concrete, and new concrete are decreasing.

\section{Conclusions}

(1) The chipping surface harshness is higher than the brushing surface's, and the cohesional strength is higher. The old concrete surface should be treated by chipping method.

(2) The interface agent has great influences on compression and rupture strength of the cohesional surface, and the cement paste is the best interface agent.

(3) With the increasing of freezing and thawing cycle times, the compression and rupture strength of the cohesional surface, old concrete, and new concrete are decreasing.

\section{References}

[1] Huicai, Xie, Gengying Li, Guangjin Xiong. Silicate Bulletin. Forum Vol. 3 (2003), p. 7-10

[2] Guangjin Xiong, Hao Jiang, Liqiang Chen. industrial architecture.Forum Vol. 31(2006), p. 71-72

[3] Suping Bi, Juhong Han. Journal of Zhengzhou Polytechnic University. Forum Vol. 22(2007), p. $12-14$

[4] Rongjun Chen, Xiaohui Wang, Rui Zeng. Journal of airforce logistics college. Forum Vol. 24(2013), p. 55-58 